\title{
Cotidiano e práticas educativas parentais: a percepção das famílias de crianças em sofrimento psíquico
}

\section{Daily life and educational parenting practices: the perception of families of children undergoing psychological stress}

\author{
Maria Fernanda Barboza Cid ${ }^{1}$, Gabriella da Cruz Santos ${ }^{2}$, \\ Carolina Elisabeth Squassoni ${ }^{3}$
}

http://dx.doi.org/10.11606/issn.2238-6149.v28i2p190-197

Cid MFB, Santos GC, Squassoni CE. Cotidiano e práticas educativas parentais: a percepção das famílias de crianças em sofrimento psíquico. Rev Ter Ocup Univ São Paulo. 2017 maio-ago.;28(2):190-7.

RESUMO: Objetivo: identificar as percepções de responsáveis por crianças em sofrimento psíquico sobre as atividades que desenvolvem com elas, as práticas educativas que utilizam em seu cotidiano e sobre como compreendem a influência destas no comportamento das crianças. Participaram 10 responsáveis por crianças de 6 a 10 anos, vinculadas a um Programa de Terapia Ocupacional em Saúde Mental Infantojuvenil. Foi utilizado roteiro de entrevista semiestruturado, cujos resultados foram analisados pela técnica de análise de conteúdo. Observouse que grande parte dos participantes possui um cotidiano de atividades compartilhadas com suas crianças, rotina de atividades programadas e com horários, responsabilidades e regras na família; adotam comportamentos afetivos com frequência e diversificam suas práticas educativas de acordo com o contexto em que ela é demandada. Verificou-se não haver um perfil de estratégias e de cuidado parental comum a todos os participantes, pois o padrão da relação de cada família norteia as ações dos pais com as crianças, a depender da dinâmica de cada contexto. Tais resultados indicam pontos importantes a serem considerados em ações para as crianças em sofrimento psíquico e suas famílias.

DESCRITORES: Saúde mental; Desenvolvimento infantil; Poder familiar; Criança; Relações familiares; Atividades cotidianas.
Cid MFB, Santos GC, Squassoni CE. Daily life and educational parenting practices: the perception of families of children undergoing psychological stress. Rev Ter Ocup Univ São Paulo. 2017 May-Aug.;28(2):190-7.

ABSTRACT: Objective: to identify the perceptions of parents of children undergoing psychological stress on the activities they develop together, the educational practices they use in their daily life, and how they see these practices influence the children's behavior. Ten parents of children aged from 6 to 10 years linked to the Occupational Therapy Program for Children's and Adolescent's Mental Health participated in this study. We used a semi-structured interview script, whose results we analyzed using the content analysis technique. We observed that most participants share daily life activities with their children, have a routine with planned activities and schedules, with responsibilities and rules in the family context; parents often adopt affective behaviors and use different educational practices according to the situation. We verified there are no parenting educational strategies that represent all participants, because the relationship pattern depends on the context of each family. These results indicate important points to be considered in actions for children undergoing psychological stress and their respective families.

KEYWORDS: Mental health; Child development; Parenting; Child; Family relations; Activities of daily living

O trabalho apresentado neste manuscrito se trata de parte dos resultados do Relatório de Iniciação Científica realizado pela segunda autora. Foi apresentado: Congresso de Iniciação Científica da UFSCar, 2013-2014; XVIII Semana de Estudos em Terapia Ocupacional da UFSCar; I Simpósio de Trabalhos de Conclusão de Curso e de Iniciação Científica de Terapia Ocupacional da UFSCar, 2014; 67ª Reunião Anual da Sociedade Brasileira para o Progresso da Ciência, 2015.

Os autores declaram não haver conflitos de interesse.

Trabalho financiado pelo Conselho Nacional de Desenvolvimento Científico e Tecnológico - PIBIC/CNPq/UFSCar.

1. Professora Adjunta do Departamento de Terapia Ocupacional e do Programa de Pós-Graduação em Terapia Ocupacional (PPGTO) da Universidade Federal de São Carlos (UFSCar). E-mail: mariafernandacid@gmail.com

2. Terapeuta Ocupacional pela Universidade Federal de São Carlos, especialista em saúde mental infantojuvenil pela Faculdade de Medicina de Botucatu - Unesp. E-mail: gabriella.csantos@hotmail.com

3. Doutora em Educação Especial pelo Programa de Pós-Graduação em Educação Especial da UFSCar. Pós-Doutorado pelo Programa de Pós-Graduação em Terapia Ocupacional (PPGTO) da UFSCar. E-mail: carolinasquassoni15@gmail.com

Endereço para correspondência: Maria Fernanda Barboza Cid, Universidade Federal de São Carlos, Rod. Washington Luís, km 235, CEP 13565-905, São Carlos, SP, Brasil, Telefone: (16) 3351 8342/ 3306 6626, e-mail: mariafernandacid@gmail.com 
Cid MFB, et al. Cotidiano e práticas educativas parentais. Rev Ter Ocup Univ São Paulo. 2017 maio/ago.;28(2):190-7.

\section{INTRODUÇÃO}

saúde mental infantil pode ser
compreendida como um elenco de
habilidades adaptativas que envolvem aspectos emocionais, comportamentais e sociais ${ }^{1,2,3}$. No entanto, a presença de dificuldades relacionadas à saúde mental, o sofrimento psíquico, pode ser entendido como alterações emocionais ou comportamentais que causam prejuízos no funcionamento do sujeito, em diferentes níveis de gravidade, sendo que esta problemática vem crescendo na população infantojuvenil ${ }^{4}$.

Frente a essa realidade, a política brasileira de saúde mental aponta que se uma criança ou adolescente apresentar algum grau de sofrimento psíquico, isso deverá ser considerado de forma ampliada, considerando que ele pode ser causado por motivos de ordem variada, tais como na relação consigo, com a família ou com outras instituições sociais ${ }^{5}$.

Nessa direção, estudos mostram que características presentes no contexto familiar (como por exemplo, violência intrafamiliar) são os mais envolvidos na determinação da saúde mental infantil $1^{1,2,6,7}$.

Assim, considerando que a família se caracteriza, dentre outros aspectos, por proporcionar relações de afeto e de compromisso entre os membros, e, pensando especificamente na relação entre criança/adolescente e seu responsável, entende-se que a compreensão de práticas e estilos parentais contribui para o melhor entendimento deste processo relacional e de seu impacto na saúde mental infantil ${ }^{1,8}$.

As Práticas Educativas Parentais são caracterizadas pelas diversas estratégias e técnicas utilizadas pelos pais, permeadas pela necessidade de cuidar, educar e promover o desenvolvimento dos filhos; orientar para o desenvolvimento de autonomia e responsabilidade e para que se desenvolvam adaptativamente, de acordo com as regras sociais e com os valores culturais aceitos numa determinada época histórica e num contexto social específico ${ }^{9}$. Alguns autores internacionais e nacionais têm se debruçado em investigações que relacionam a saúde mental de crianças com as práticas parentais utilizadas pelos responsáveis.

$\mathrm{Yu}$ et al. ${ }^{10}$, visando investigar crianças com risco para o desenvolvimento de problemas comportamentais e sociais, bem como a influência das variáveis práticas parentais e uso do tempo livre no desenvolvimento de tais problemas, avaliaram 4936 crianças australianas de quatro e cinco anos de idade. Os resultados encontrados revelaram que as principais variáveis relacionadas aos problemas sociais e comportamentais nas crianças foram a utilização, pelos responsáveis, de práticas parentais pouco consistentes e hostis na educação das crianças. As autoras discutem esse resultado, apontando que essas práticas parentais podem gerar estresse e medo nas crianças, interferindo na regulação do humor das mesmas e as levando a apresentarem reações imaturas e impulsivas ${ }^{10}$.

No Brasil, Salvo e colaboradore ${ }^{11}$ desenvolveram uma pesquisa com o objetivo de levantar quais práticas parentais avaliadas pelo Inventário de Estilos Parentais de Gomide ${ }^{12}$ poderiam prejudicar a saúde mental. Foram participantes, 30 crianças, com idades entre 11 e 13 anos, da rede pública de ensino, e um responsável. Os resultados revelaram que as práticas parentais monitoria positiva e comportamento moral são variáveis que favorecem comportamentos pró-sociais, e sua falta somada às práticas negativas são preditoras de dificuldades relacionadas à saúde mental ${ }^{11}$.

Vale observar que na literatura brasileira, o trabalho de Gomide $^{13}$ é destaque na área das práticas educativas parentais. Tal autora divide os estilos parentais em Estilo Parental Positivo e Estilo Parental Negativo, resultantes de sete práticas educativas, as quais são divididas também em práticas educativas positivas (monitoria positiva e comportamento moral) e práticas educativas negativas (negligência, abuso físico e psicológico, disciplina relaxada, punição inconsistente, monitoria negativa).

Autores indicam que é possível que toda família utilize tanto de práticas educativas positivas quanto negativas, podendo utilizar a combinação de várias estratégias, de acordo com as diferentes situações ${ }^{14}$. O que vai determinar se o estilo parental é de risco ou não para a saúde mental de crianças, porém, é a frequência e o contexto com que as diferentes práticas são utilizadas pelos pais na interação com seus filhos ${ }^{15}$.

Nessa direção, não é possível afirmar que determinadas práticas e estilos são melhores que outros sem considerar a complexidade das relações familiares e as variáveis que influenciam nas práticas dos pais em relação ao cuidado dos filhos ${ }^{9}$.

Alguns desses aspectos foram considerados e investigados no estudo de Cid e Matsukura ${ }^{2}$, que estimou a prevalência de problemas de saúde mental em estudantes do primeiro ciclo do ensino fundamental, e investigou os fatores de risco e proteção representados pelo suporte social do responsável, práticas e estilos parentais, saúde mental do responsável e variáveis relativas à estrutura e contexto familiar. Os resultados apontaram que a saúde mental infantil esteve significativamente relacionada às práticas e estilos parentais de risco, presença de pelo 
Cid MFB, et al. Cotidiano e práticas educativas parentais. Rev Ter Ocup Univ São Paulo. 2017 maio/ago.;28(2):190-7.

menos um transtorno mental no responsável, e existência de brigas na família. Além disso, a existência, na família, de responsabilidades e regras conhecidas e cumpridas por todos os membros se relacionou ao comportamento prósocial das crianças.

Frente aos resultados encontrados, as autoras apontam para a necessidade de se compreender a saúde mental infantil a partir de um contexto mais amplo, no qual os diversos fatores presentes no cotidiano das famílias sejam considerados nas ações de promoção, prevenção e tratamento em saúde mental e, nessa direção, que tais ações possam ser desenvolvidas de forma intersetorial, a partir de articulação entre os diferentes setores públicos que assistem crianças e adolescentes ${ }^{2}$.

A literatura nacional recente na área das práticas educativas parentais tem sido explorada ${ }^{3,16,17}$, entretanto, são poucos os estudos que se debruçam sobre a percepção dos pais a respeito das práticas parentais utilizadas junto a suas crianças que vivenciam a experiência do sofrimento psíquico, para além de padrões estabelecidos pelos instrumentos padronizados.

Diante disso, e da importância de conhecer os significados que pais e mães têm sobre: o sofrimento psíquico da criança, parentalidade, família, cuidados; e considerando também a importância e possível ligação dessas práticas como um fator de favorecimento da saúde mental, este estudo teve por objetivos: identificar, a partir da visão de responsáveis por crianças que vivenciam a experiência do sofrimento psíquico, o cotidiano de atividades que desenvolvem juntamente com seus filhos; as práticas educativas parentais que utilizam em seu cotidiano; e a influência das práticas utilizadas no comportamento das crianças, considerando facilidades e dificuldades nesta interação.

\section{MÉTODO}

Participaram deste estudo, 10 responsáveis por crianças usuárias de um Programa de Terapia Ocupacional em Saúde Mental Infantojuvenil que acontece em um serviço escola localizado no interior do estado de São Paulo, sendo nove mães e um pai, com idade entre 25 e 47 anos. Oito participantes são casados, uma participante é solteira e uma participante tem união estável. Todos os participantes têm relação parental direta com a criança (pai/ mãe) referida no estudo, e residem com elas.

Das crianças correspondentes, as idades variaram de 6 a 10 anos, sendo nove meninos e uma menina. Todas as crianças frequentam a escola e cursam entre o $1^{\circ}$ ano $\mathrm{e}$ $5^{\circ}$ ano do ensino fundamental.
As crianças apresentavam sofrimento psíquico manifestado a partir de dificuldades no comportamento, nas relações pessoais e na expressão do afeto e emoções, sem diagnóstico definido. Essas crianças chegam ao serviço a partir de encaminhamentos formais advindos de outros serviços de saúde do município, encaminhamentos de escolas e outros equipamentos sociais ou demanda espontânea.

O processo de identificação dos participantes e coleta de dados ocorreu entre o período de agosto de 2014 a julho de 2015. Para a localização e identificação dos participantes, as pesquisadoras entraram em contato com o referido serviço que acompanha crianças e adolescentes que apresentam o sofrimento psíquico. O projeto foi apresentado e a autorização para que o estudo ocorresse nas suas dependências foi concedida, assim como aprovado pelo Comitê de Ética em Pesquisa em Seres Humanos da UFSCar (CAAE de $\mathrm{n}^{\circ}$ 19413013.5.0000.5504).

Feito isso, os profissionais que realizam as ações junto às crianças foram contatados, os objetivos do estudo apresentados e solicitada a identificação de crianças vinculadas ao serviço que se enquadrariam nos critérios de participação: idade entre 6 e 10 anos; encaminhadas ao Programa de Terapia Ocupacional em Saúde Mental Infantojuvenil devido a dificuldades comportamentais, relacionais ou emocionais sem, necessariamente um diagnóstico definido; sendo excluídos responsáveis por crianças com dificuldades mais graves, tais como autismo, por exemplo.

Identificadas as crianças, foram feitos contatos com suas famílias através de telefonemas a fim de convidá-las para participar do estudo e agendamento da entrevista. Aponta-se que se buscou agendar as entrevistas no serviço, preferencialmente nos dias de atendimento das crianças. Cabe ressaltar que a pesquisadora responsável pelo contato com as famílias e coleta de dados não possuía vínculo com o serviço.

Para a coleta de dados foi utilizado Roteiro de Entrevista Semiestruturado desenvolvido pelas pesquisadoras, composto por 31 questões que abordavam a percepção dos responsáveis a respeito do cotidiano de atividades que desempenham junto aos seus filhos; das práticas educativas parentais adotadas no cotidiano e o que consideram ajudar e/ou atrapalhar na criação/ educação das crianças.

Destaca-se que todos os participantes assinaram o Termo de Consentimento Livre e Esclarecido, como condição para participação no estudo.

Todas as entrevistas foram gravadas e transcritas na íntegra. Os resultados deste estudo foram analisados através da técnica de análise de conteúdo, que analisa e interpreta 
Cid MFB, et al. Cotidiano e práticas educativas parentais. Rev Ter Ocup Univ São Paulo. 2017 maio/ago.;28(2):190-7.

o conteúdo que é manifestado pelas falas dos participantes por meio de procedimentos sistemáticos e objetivos ${ }^{18}$.

Os relatos foram desmembrados em unidades de registro semelhantes e posterior definição das categorias do conteúdo. As unidades de registro foram organizadas por temas de acordo com o que tinha sido definido previamente pelo roteiro de entrevista semiestruturado. Em seguida, foi feita a elaboração e descrição das categorias presente nas unidades de registro, a partir dos sentidos existentes no conteúdo das unidades de registro ${ }^{18}$.

\section{RESULTADOS}

A partir da análise das entrevistas, 2 temáticas foram identificadas: cotidiano e rotina da criança e da família e práticas educativas parentais. Tais resultados serão descritos a seguir e ilustrados com relatos dos participantes, os quais serão identificados pela letra $\mathrm{P}$, seguida dos números de 1 a 10.

A temática cotidiano e rotina da criança e da família envolve quais são as atividades que os participantes realizam junto com seus filhos.

Quatro participantes relataram levar a criança às suas tarefas e compromissos do dia a dia, incluindo lugares que a criança tenha desejo de ir; ou que a criança acompanha o responsável em suas tarefas e compromissos:

P9: “(...) Ela vai muito comigo no grupo de louvor. Ela gosta de ir. (...) dar uma volta no zoológico (...). Se precisa levar ao médico... (...) vou ao supermercado, ela vai junto. (...)”.

Outras atividades realizadas com as crianças são brincar, assistir TV e passear:

P1: “(...) Gosta de ficar assistindo televisão, eles me chamam para assistir filme, pegadinhas, essas coisas que eles gostam. Nos ensaios também, eu vou em todos (...)”.

Ao relatar sobre o que faz junto com a criança, um responsável relata as dificuldades da criança:

P3: “(...) A gente vai andar no condomínio, levo ele no parque (...) Vira e mexe ele quer inventar uma coisa, mas ele quer que os outros façam para ele (...), ai ele abandona. Ele é bom para dar ideia, para dar ordem. (...) Mas ele não vai (...)".

Sobre a existência de uma rotina de atividades no cotidiano da criança, sete participantes relataram que a criança tem uma rotina de atividades diárias, com horários, incluindo atividades fora de casa (escola, atendimento terapêutico em saúde mental), refeições e atividades de vida diária, e algumas atividades em casa (lição de casa, arrumar a cama, cuidar dos animais de estimação):

\footnotetext{
P9: “(...) É estipulado todo sábado o horário da lição porque o domingo é o dia em que vamos à igreja, (...) Quando ela está em casa é horário certo de comer, horário de dormir (...). Como a escola é rígida, tem esses horários, então eu procuro manter sempre esses horários em casa também. (...)".
}

No que tange as práticas educativas parentais adotadas no cotidiano das famílias, emergiram os seguintes achados: existência de regras e responsabilidades na família; existência de responsabilidades da criança; estratégias para repreender e dar limites para a criança frente a um comportamento/ atitude que julga inadequada; formas de lidar com a criança frente a um comportamento/ atitude considerada positiva/correta; demonstração de afeto pela criança; percepção de como é educar a criança; e maneira como se orienta para educar a criança.

Cinco participantes relataram que há regras e responsabilidades na família, que todos conhecem e cumprem, como regras de convivência, responsabilidades em casa, refeições em família, e outros:

P7: “(...) Eles têm hora para dormir, eles têm que arrumar o quarto deles (...). A roupa sempre no cesto (...). Eu não admito que ele responda para mim (...). Cuidar do quarto deles, do livro, e a tarefa (...). Eu não deixo comer na frente do computador (...), eu não admito também que bata neles (...)”.

Sete participantes relataram que a criança tem responsabilidades. Deste total, quatro participantes relataram que dentre as responsabilidades estão cuidar de animais de estimação, ajudar em afazeres domésticos e fazer a lição de casa:

P7: “(...) Eu fiz uma lista para eles dois poderem me ajudar. Então eu coloquei: lavar a área, (...) enxugar a louça do almoço e guardar a louça do jantar (...), eles organizam o próprio quarto, e os brinquedos. (...), não pode deixar esparramado (...)".

Dois participantes elencaram como responsabilidade da criança, cuidar das próprias coisas: 
Cid MFB, et al. Cotidiano e práticas educativas parentais. Rev Ter Ocup Univ São Paulo. 2017 maio/ago.;28(2):190-7.

P9: “(...) No fim de semana ela tem que dar ração para os cachorrinhos dela, que são dela (...). Tem um passarinho lá, então é responsabilidade dela olhar, ver se tem água (...). Já que ela quer ter, então, ajuda a cuidar (...)".

Sobre as estratégias que os participantes utilizam para repreender e dar limites para a criança frente a um comportamento e/ou atitude que consideram inadequadas, dois participantes indicaram o castigo como forma de repreender e dar limites à criança:

P1: "Eu tiro. Eu desligo o vídeo game, eu desligo o computador, eu tiro tudo. Não vai brincar na rua, entendeu? Eu faço isso. Bater, eu não bato. Eu deixo de castigo, deixo pensando (...)”.

Quatro participantes relataram que utilizam diferentes estratégias a depender da situação:

P10: “(...) Eu explico uma vez, advirto na segunda, castigo na terceira, e bato na última (...). Se ainda assim não fizer, eu deixo lá parado, mas aí não vai brincar, (...) não vai fazer nada (...)”.

Três participantes relataram que conversar e impor autoridade são as estratégias mais utilizadas para dar limites:

P6: "Explico para ele que está errado, o porquê que está errado (...), eu repreendo no começo, mas no final acaba virando uma conversa, entendeu? (...) A não ser que eu vejo que ele está passando dos limites (...) aí a autoridade vem em primeiro lugar".

Todos os participantes relataram que elogiam a criança frente a um comportamento/ atitude considerada como positiva, boa, e/ou correta. Desses, quatro relataram que além do elogio, também reagem com gestos de carinho, como abraço, beijo, verbalizar que está orgulhoso; incentivando a criança a continuar nesse caminho; ou recompensando a atitude.

P10: (...) Se em cima daquilo que ele fez de bom ele fica com dúvida, eu abraço ele, pego no colo, falo para ele continuar a fazer as coisas dele... Tudo o incentivando para ele não parar (...). Então, se ele está bonzinho, ele está obedecendo (...) eu vou lá, dou um jeito de recompensar ele de alguma maneira (...) eu faço alguma coisa que ele gosta (...)”.
Nove participantes relataram que, além de gestos de carinho, eles demonstram afeto pela criança também por meio de conversa, orientação, elogios e falam que amam a criança:

P6: "Beijo, abraço, muita brincadeira (...). Falo que amo muito ele (...). Ele fala muito que me ama também (...). Quando ele faz uma coisa muito legal eu o elogio”.

Os participantes identificaram e exemplificaram as facilidades e as dificuldades no processo de educar a criança. Sete participantes relataram que as facilidades envolvem seu comportamento e adoção de práticas pela família:

P6: “(...) Carinho, atenção, brinco com ele (...). Com muito carinho, muita atenção, muito amor. Então essa parte é a mais fácil do mundo (...)”.

No que diz respeito às dificuldades, quatro participantes relataram que estas incluem o comportamento da criança e suas dificuldades relacionadas ao sofrimento psíquico:

P2: “(...) Dificil fazer ele entender tudo isso (...). É difícil dizer que ele precisa tomar o remédio. É difícil! (...). A hora que você acha que está dando certo (...), passam 15 dias, passa um mês, assim (...) De repente acontece alguma coisa e (...) tudo fica dificil”".

Outros quatro participantes disseram que as dificuldades envolvem insegurança na educação e no processo de lidar frente a um comportamento do filho:

P6: "Difícil. Por causa da insegurança de você saber se aquilo está certo ou não. Por mais que você tente fazer tudo corretamente, é impossivel (...). A minha maior dificuldade na educação dele é o medo de errar (...)".

A respeito da maneira como os pais se orientam para educar a criança, dois participantes relataram ter como referência a educação que tiveram, filtrando o que foi positivo e modificando aquilo que não foi:

P6: “(...) Procuro pensar antes de fazer alguma coisa (...), procuro passar para ele o que eu acho certo e o que eu acho errado, de acordo com o que aprendi, do que eu vejo do mundo (...)". 
Cid MFB, et al. Cotidiano e práticas educativas parentais. Rev Ter Ocup Univ São Paulo. 2017 maio/ago.;28(2):190-7.

Três participantes apresentaram estratégias, incluindo orientações recebidas por algum profissional (de saúde, de educação), programas de TV, forma como foi educado, leituras, e outros:

P7: "Tudo que eu passei. O jeito que eu fui criada. O jeito que minha sogra criou os filhos dela (...). Ás vezes alguma coisa que eu vejo na TV. Quando eu não sei o que fazer eu venho e peço orientação para C., ela me ajuda também (...). Peço orientação na escola também (...). Estou fazendo com ele o que eu gostaria que meus pais tivessem feito comigo (...)”.

\section{DISCUSSÃO}

A partir dos resultados apresentados, identificouse que todos os participantes possuem atividades compartilhadas com suas crianças, sendo elas rotineiras ou não, tanto durante a semana quanto aos finais de semana. A natureza das atividades diz respeito em sua maioria a acompanhar as crianças nos seus compromissos diários, mas também em atividades de lazer, como brincar, passear e assistir TV.

Observou-se que sete, das dez crianças, possuem rotina de atividades programadas, estruturadas, como tarefas escolares, terapia, tarefas em casa; e também possuem responsabilidades e regras no contexto familiar e rotina de horários.

Alguns autores apontam que promover rotinas familiares, assim como o estabelecimento de regras, o envolvimento parental nas atividades com as crianças e supervisão de tais atividades podem contribuir para a saúde mental infanti1 ${ }^{13,19,20}$.

Muñiz et al. ${ }^{20}$ destacam que a presença de rotinas no contexto familiar pode ter o potencial de impactar positivamente a saúde mental de crianças pequenas antes de ingressar na escola, pois tal participação nas rotinas familiares é um marcador de maior organização familiar, estabelecendo expectativas no ambiente doméstico, e proporcionando uma sensação de segurança e de pertencimento, além de influenciar positivamente no desenvolvimento dessas habilidades que são essenciais para adaptação em ambientes escolares estruturados, como também em outros ambientes.

Porém, tais autores reforçam ainda que essa relação direta entre a participação da criança na rotina familiar e sua saúde mental é inconclusiva devido a limitação dos estudos que visam analisar esta questão. Tais limitações dizem respeito à transversalidade dos estudos (embora também aconteça com estudos longitudinais), a generalização de pequenas amostras, diferentes abordagens para operacionalizar as variáveis da rotina e falta de diversidade entre as amostras de estudo ${ }^{20}$.

Os autores ponderam, então, que não se pode distinguir se é a prática da rotina que provoca impactos positivos no comportamento das crianças ou se a qualidade da interação pai-filho presente durante a rotina é o que leva a tal associação ${ }^{20}$.

No que diz respeito às práticas educativas e considerando a literatura da área, os resultados obtidos no presente estudo indicam que, parece haver o predomínio por parte dos participantes de práticas educativas parentais positivas em detrimento das práticas educativas negativas. Segundo Salvo e colaboradores ${ }^{11}$, através da monitoria positiva, por exemplo, caracterizada pelo real interesse e acompanhamento dos filhos, os pais demonstram afeto, são disponíveis e demonstram manifestações físicas de carinho e mantêm contatos sociais com a criança, o que faz o filho sentir-se amado e protegido.

No que se refere às estratégias de repreensão e do estabelecimento de limites à criança quando esta tem um comportamento ou atitude que, na opinião do participante, é inadequada, os responsáveis relataram que utilizam diferentes estratégias a depender da situação, como conversas, imposição de autoridade, e castigo. Os participantes disseram, também, que as estratégias disciplinares utilizadas tendem a funcionar em alguns momentos, não sendo eficientes em todas as situações.

Nesse sentido, segundo os próprios participantes, a adoção de certas práticas educativas varia e depende da situação, do comportamento da criança, e do que se mostra efetivo. Além do que, vale considerar outros fatores e situações externas à relação mãe-criança que também podem interferir, como o estado de humor da mãe, problemas no trabalho e conjugais; número de filhos; responsabilidades domésticas; dificuldade emocional da criança, entre outros.

Tais constatações suscitam a reflexão sobre o cuidado que precisa ser feito ao se caracterizar as práticas educativas. Conforme aponta Macarini et al. ${ }^{9}$, não é possível afirmar que determinadas práticas são melhores que outras sem considerar o contexto, a dinâmica familiar, as características específicas da criança e também dos pais, a história de criação e desenvolvimento desses pais, assim como suas percepções sobre as práticas adotadas, e o contexto sociocultural em que estão inseridos.

Com relação a percepção dos pais a respeito das facilidades e dificuldades ao lidar com a criança, os resultados demonstraram questões referentes ao comportamento da criança e as dificuldades relacionadas 
Cid MFB, et al. Cotidiano e práticas educativas parentais. Rev Ter Ocup Univ São Paulo. 2017 maio/ago.;28(2):190-7.

ao sofrimento psíquico vivenciado pela mesma, e a insegurança na educação e no agir frente a um comportamento do filho com sofrimento psíquico.

Apartir destes resultados, hipotetiza-se que a presença do sofrimento psíquico na criança acarreta uma sobrecarga física e emocional, especialmente naqueles do convívio familiar. De acordo com Colvero et al. ${ }^{21}$ os familiares que procuram a ajuda e suporte dos serviços de saúde mental e de seus profissionais apresentam demandas das mais variadas ordens, como a dificuldade para lidar com as situações de crise vividas, com os conflitos familiares emergentes, com a culpa, com o pessimismo por não conseguir ver saída aos problemas enfrentados, pelo isolamento social a que ficam sujeitos, pelas dificuldades materiais da vida cotidiana, pelas complexidades do relacionamento com a pessoa em sofrimento, pela expectativa frustrada de cura, bem como pelo desconhecimento da doença propriamente dita, dentre tantas outras insatisfações.

Além disso, a ausência de uma marca no sofrimento psíquico, como possui a deficiência física, por exemplo, não permite uma identificação e reconhecimento social de maneira imediata. Por isso, o adoecimento psíquico da criança acaba sendo omitido em detrimento de uma leitura moral, que atribui os comportamentos inadequados à má educação, culpabilizando os pais/ responsáveis como salientado por Ferreira ${ }^{22}$.

De toda forma, é importante considerar que, independente das dificuldades e do sofrimento psíquico que a criança possa apresentar, a ação de educar e cuidar de filhos por si só já gera sentimentos de insegurança, medos e incertezas ${ }^{23}$.

Para Biasoli-Alves ${ }^{24}$ as transformações observadas no decorrer das últimas décadas no modo de conceber a relação pais e filhos parecem ser fruto do conhecimento técnico científico, que acaba gerando insegurança nos pais quanto à forma de pensar a educação das gerações mais novas. Neste sentido, Ribeiro ${ }^{25}$ destaca que nos dias atuais os pais estão imersos numa grande quantidade de informação que provém de profissionais, dos meios de comunicação ou mesmo dos amigos e/ou membros da família.

Enfatiza-se a questão e reflexão suscitada por este estudo no que diz respeito à dificuldade, e talvez impossibilidade de haver um padrão de cuidado parental que seja perfeito e viável para a maioria das pessoas. Muitos estudos sobre práticas educativas parentais buscam caracterizar tais práticas num viés do "positivo ou negativo; benéfico ou prejudicial", objetivando a partir disso, intervenções que atuem justamente para atingir um padrão ideal, produzindo ações de causa e efeito. Acredita-se, portanto, ser importante o investimento em estudos que investiguem as práticas educativas parentais numa perspectiva subjetiva, considerando as particularidades sobre o entendimento destas questões e considerando a diversidade das relações familiares.

\section{CONCLUSÕES}

O foco deste estudo foi identificar a partir da percepção dos responsáveis de crianças com sofrimento psíquico, como se dão as atividades cotidianas, as relações familiares e as práticas educativas parentais adotadas, diante de uma importante variável que já se faz presente no cotidiano dessas crianças e suas famílias, que é o sofrimento psíquico.

Acredita-se que este estudo atingiu os objetivos propostos e contribuiu com a produção de conhecimento da área das práticas educativas parentais, especialmente no que tange famílias de crianças que vivenciam a experiência do sofrimento psíquico, bem como sinalizou elementos a serem pautados nos processos de planejamento e desenvolvimento de intervenções familiares nos contextos de cuidado em saúde mental infantojuvenil.

A partir dos resultados, foi possível refletir sobre a necessidade de se considerar, tanto nas pesquisas quanto nas práticas direcionadas ao cuidado em saúde mental infantil, a complexidade das relações e dinâmicas familiares e os fatores que podem estar envolvidos no processo de adoção de determinadas práticas educativas parentais no cotidiano, com crianças que vivenciam a experiência do sofrimento psíquico, ampliando a compreensão sobre o que é entendido por positivo ou negativo.

Contudo, este estudo apresentou algumas limitações, tais como o número reduzido de participantes, as informações terem se baseado no depoimento de apenas um único entrevistado da família, e a realização da pesquisa em um único serviço especializado.

Considerando o caráter exploratório do presente estudo e as limitações apresentadas novas investigações que focalizem esta temática são importantes no sentido de subsidiar reflexões e planejamento de práticas com foco protetivo para as crianças em sofrimento psíquico e suas famílias.

Contribuição dos autores: Todos os autores trabalharam na concepção e na redação final da pesquisa. O segundo autor foi responsável pela coleta, tratamento e apresentação dos dados. 
Cid MFB, et al. Cotidiano e práticas educativas parentais. Rev Ter Ocup Univ São Paulo. 2017 maio/ago.;28(2):190-7.

\section{REFERÊNCIAS}

1. Cid MFB. Cotidiano familiar: refletindo sobre a saúde mental infantil e a prática de atividades familiares. Rev Ter Ocup Univ São Paulo. 2015;3(26):428-38. doi: 10.11606/issn.2238-6149. v26i3p428-438.

2. Cid MFB, Matsukura TS. Problemas de saúde mental em escolares e seus responsáveis: um estudo de prevalência. Rev Ter Ocup Univ São Paulo. 2014;25(1):1-10. doi: 10.11606/ issn.2238-6149.v25ilp1-10.

3. Matsukura TS, Fernandes ADSA, Cid MFB. Saúde mental infantil em contextos de desvantagem socioeconômica: fatores de risco e proteção. Cad Ter Ocup UFSCar. 2014;2(22):251-62. doi: $10.4322 /$ cto.2014.047.

4. World Health Organization. The World Health Report 2001: mental health: new understanding, new hope. Geneva; 2001.

5. Brasil. Ministério da Saúde. Conselho Nacional do Ministério Público. Atenção psicossocial a crianças e adolescentes no SUS: tecendo redes para garantir direitos. Brasília; 2014. Disponível em: http://bvsms.saude.gov.br/bvs/publicacoes/atencao psicossocial_criancas_adolescentes_sus.pdf.

6. Sá DGF, Bordin IAS, Martin D, Paula CSP. Fatores de risco para problemas de saúde mental na infância/adolescência. Psicol Teor Pesqui. 2010;26(4):643-52. doi: 10.1590/S010237722010000400008 .

7. Ferrioli SHT, Marturano EM, Puntel LP. Contexto familiar e problemas de saúde mental infantil no Programa Saúde da Família. Rev Saúde Pública. 2007;41(2):251-9. doi: 10.1590/ S0034-89102006005000017.

8. Souza MTS, Oliveira AL. Fatores de proteção familiares, situações de risco, comportamentos e expectativas de jovens de baixa renda. In: Dell'Aglio DD, Koller SH, organizadores. Adolescência e juventude: vulnerabilidade e contextos de risco e proteção. São Paulo: Casa do Psicólogo; 2011.

9. Macarini SM, Martins GDF, Minetto, MFJ, Vieira ML. Práticas parentais: uma revisão da literatura brasileira. Arq Bras Psicol. 2010;1(62):119-34. Disponível em: http://pepsic.bvsalud.org/ scielo.php?script=sci_arttext\&pid=S1809-52672010000100013.

10. Yu M, Ziviani J, Baxter J, Haynes M. Time use, parenting practice and conduct problems in four- to five-year-old Australian children. Aust Occupl Ther J. 2010;57(5):284-92. doi: $10.1111 / j .1440-1630.2009 .00818 . x$.

11. Salvo CG, Silvares EFM, Toni M. Práticas educativas como forma de predição de problemas de comportamento e competência social. Estud Psicol. 2005;2(22):187-95. doi: 10.1590/S0103-166X2005000200008.

12. Gomide PIC. Inventário de Estilos Parentais - IEP: modelo teórico, manual de aplicação, apuração e interpretação. Petrópolis, RJ: Vozes; 2006.

Recebido em: 22.08.16

Aceito em: 21.04.17
13. Gomide PIC. Estilos parentais e comportamento anti-social. In: Del Prette A, Del Prette Z, Del Prette, organizadores. Habilidades sociais, desenvolvimento e aprendizagem. Campinas: Alínea; 2003. p.21-60

14. Weber L, Prado P, Viezzer A, Brandenburg O. Identificação de estilos parentais: o ponto de vista dos pais e dos filhos. Psicol Reflex Crit. 2004;3(17):323-31. doi: 10.1590/S010279722004000300005 .

15. Pinheiro DPN. Estilo parental: uma análise qualitativa. Curitiba [Mestrado]. Paraná: Universidade Federal do Paraná; 2003.

16. Leme VBR, Marturano EM. Preditores de Comportamentos e Competência Acadêmica de Crianças de Famílias Nucleares, Monoparentais e Recasadas. Psicol Reflex Crit. 2014;1(27):15362. doi: 10.1590/S0102-79722014000100017.

17. Marin AH, Martins GDF, Freitas APCO, Silva IM, Lopes RCS, Piccinini CA. Transmissão intergeracional de práticas educativas parentais: evidências empíricas. Psicol Teor Pesqui. 2013;2(29):123-32. doi: 10.1590/S0102-37722013000200001.

18. Bardin L. Análise de conteúdo. Lisboa, Portugal: Edições; 1977.

19. Cid MFB, Matsukura TS, Cia F. Relações entre a saúde mental de estudantes do ensino fundamental e as práticas e estilos parentais. Mundo Saúde. 2015;4(39):504-13. doi: 10.15343/0104-7809.20153904504513.

20. Muñiz EI, Silver EJ, Stein REK. Family routines and socialemotional school readiness among preschool-age children. J Dev Behav Pediatr. 2014;2(35):93-9. doi: 10.1097/ DBP.0000000000000021.

21. Colvero LA, Ide CAC, Rolim MA. Família e doença mental: a difícil convivência com a diferença. Rev Esc Enferm USP. 2004;2(38):197-205. doi: 10.1590/S0080-62342004000200011.

22. Ferreira T. Introdução - Sob o manto da deficiência. In: Ferreira $\mathrm{T}$, organizador. A criança e a saúde mental - enlaces entre a clínica e a política. Belo Horizonte: Autência/FCH - FUMEC; 2004. p.13-38.

23. Patias ND, Siqueira AC, Dias ACG. Práticas educativas e intervenção com pais: a educação como proteção ao desenvolvimento dos filhos. Mudanças. 2013;1(21):29-40. doi: 10.15603/2176-1019/mud.v21n1p29-40.

24. Biasoli-Alves ZMM. A questão da disciplina na prática de educação da criança, no Brasil, ao longo do século XX. Veritati. 2002;2(2):243-59. Disponível em: http://bdpi.usp.br/single. php?_id=001294420. Acesso em 18/05/2017.

25. Ribeiro MJS. Ser família: construção, implementação de um programa de educação parental [dissertação]. Braga: Universidade do Minho; 2003. 